Rev. Interd. em Cult. e Soc. (RICS), São Luís, v. 6, n. 1, p. 173- 186, jan./jun. 2020

ISSN eletrônico: 2447-6498

\title{
O Lugar, A Velhice e A Mulher: Uma Leitura da Geograficidade no Conto "As Mimosas"
}

\author{
Place, Old Age and Woman: A Reading of Geographicity in the Tale "As \\ Mimosas"
}

\author{
ROSÂNGELA GUEDÊLHA DA SILVA \\ Mestra em Cultura e Sociedade pela Universidade Federal do Maranhão (PGCult-UFMA) \\ rosgued29@gmail.com
}

\section{RESUMO}

Apresenta-se a leitura do espaço no conto "As mimosas", de Teolinda Gersão, a partir do conceito de "geograficidade" teorizado por Dardel (2015). Nessa narrativa, o quarto da idosa origina lugares distintos para a mãe senil inválida e sua única filha, Luísa. As experiências de perda de lugaridade e de intenso apinhamento, vivenciadas pela filha, permitem antever a ambivalência do espaço narrativo no qual se acham inscritos o gesto da filha abnegada que cuida da mãe senil e o mascaramento da sujeição feminina. Nessa situação, pesam a condição da mulher no contexto patriarcal e a exclusão na velhice, momento em que o mundo se torna, tão somente, um espaço para a protagonista. É um estudo bibliográfico, de base qualitativa, interdisciplinar, envolvendo a Literatura e a Geografia Humanista Cultural, com aporte teórico em Tuan (2012; 2013), Dardel (2015), Relph (2014) e importantes contribuições de Beauvoir (2018) e Bosi (2006) acerca da velhice.

Palavras-chave: Geograficidade. Literatura portuguesa contemporânea. Teolinda Gersão.

\begin{abstract}
It presents the reading of space in the short story "As Mimosas", by Teolinda Gersão, based on the concept of "geographicity" theorized by Dardel (2015). In this narrative, the old woman's room it gives rise to distinct places for the invalid senile mother and her only daughter, Luisa. The experiences of loss of place and intense crowding experienced by the daughter allow us to foresee the ambivalence of the narrative space in which the gesture of the selfless daughter who cares for the senile mother and the masking of female subjection are inscribed. In this situation, weigh the condition of women in the patriarchal context and the exclusion in old age, when the world becomes only a space for the protagonist. It is a qualitative, interdisciplinary bibliographical study, involving Literature and Cultural Humanist Geography, with theoretical support in Tuan (2012; 2013), Dardel (2015), Relph (2014) and important contributions by Beauvoir (2018) and Bosi (2006) about old age.
\end{abstract}

Keywords: Geographicity. Contemporary portuguese literature. Teolinda Gersão.

\section{INTRODUÇÃO}

Este estudo apresenta uma leitura do espaço no conto "As mimosas", da obra Prantos, amores e outros desvarios (2016a), de Teolinda Gersão. É um recorte da pesquisa de conclusão de mestrado que investigou o entrelaçamento entre a produção contística da referida autora e a temática do lugar, vivenciado na velhice no mundo contemporâneo.

\footnotetext{
${ }^{1}$ Artigo submetido para avaliação em 10/10/2019 e aprovado em 20/10/2019.
} 
Rev. Interd. em Cult. e Soc. (RICS), São Luís, v. 6, n. 1, p. 173- 186, jan./jun. 2020 ISSN eletrônico: $2447-6498$

Nascida em Coimbra, em 1940, Teolinda Gersão viveu sua infância e juventude no contexto da ditadura salazarista e, após a queda do regime, em 1974, quando adulta, tem vivenciado a reestruturação democrática e a busca pela superação das marcas deixadas pelo aparelhamento ideológico ditatorial no ideário/imaginário do povo português. Essa professora universitária aposentada pertence à geração de autores pós-revolução de 74, cuja escrita é repleta de singularidades composicionais ligadas ao experimentalismo em uma flagrante intenção crítico-subversiva, na forma e no conteúdo, seguindo uma linha mais intimista. Teolinda tem regularmente publicado desde 1981 e é uma autora de grande relevância no contexto artístico contemporâneo de seu país e com projeção internacional, tendo diversos contos e romances traduzidos e recebido diversas premiações importantes, mas, no Brasil, assim como ocorre com inúmeros outros autores, infelizmente, a circulação de suas obras restringe-se quase tão somente ao meio acadêmico.

No conjunto da produção gersiana, não há veiculação explícita de ideologia única, mas de aspectos éticos e políticos ligados à visão de mundo da autora, expressos em linguagem estética envolvente. Na representação da velhice humana em suas obras, a senilidade, que é o envelhecimento com comprometimentos patológicos, tem sido um aspecto recorrente, uma vez que consiste em uma temática de intensa carga dramática para os idosos e seus familiares. Ao estilo da autora de nunca se abster dos temas cáusticos, o conto "As mimosas" enfoca essa temática, realçando a perspectiva dos familiares a partir da história centrada em Luísa, a filha que cuida da mãe senil, o que o coloca em uma aproximação intertextual com outra produção da autora, a obra Passagens (2014).

Essa narrativa se dá a partir da morte de Ana, uma idosa que finge estar acometida de Alzheimer para que a filha com quem morava, Marta, a internasse em um lar para idosos no intuito de aliviar o desgaste físico e emocional da família, sobretudo o seu e o da filha. Marta ama muito a mãe, reluta em interná-la, mas cede pela intenção de oferecer-lhe cuidados especializados, uma vez que ela (a filha) também está com idade um tanto avançada e precisa se desdobrar em várias atividades. A retomada dessa obra no conto sugere, entretanto, a composição de outro contexto de velhice: como seria se a mãe fosse de fato inválida e dependente dos cuidados de sua única filha, a quem recorresse em todas as suas aflições físicas e emocionais, e a filha almejasse conciliar o cuidado da mãe e viver outras realizações? A complexidade do tema abordado se reflete na tessitura textual, feita a partir de um jogo de ambivalências, envolvendo o espaço, o tempo e as imagens simbólicas, estando todos esses elementos imbricados na representação da relação entre a filha e a mãe, assim como de cada 
Rev. Interd. em Cult. e Soc. (RICS), São Luís, v. 6, n. 1, p. 173- 186, jan./jun. 2020 ISSN eletrônico: 2447-6498

uma delas com o mundo, de forma que o espaço vivido reflita a vida e a velhice de ambas em meio à senilidade e à condição da mulher.

Este estudo baseia-se na aproximação interdisciplinar entre a ficção literária e concepções teóricas geográficas promovidas mais incisivamente desde a década de 1960, quando muitos pesquisadores buscam promover a ruptura com os preceitos do positivismo, da visão mecanicista do mundo e do cientificismo cartesiano e seus ditames racionalistas. Essa quebra da hegemonia da formalização do conhecimento objetivo e racional amplia-se e se fortalece, de forma que, na Geografia, muitos estudiosos ligados a vertentes humanistas e culturais trabalham com a concepção de espaço geográfico, ou seja, o lugar existencial onde o homem é compreendido em uma relação orgânica com a Terra (TUAN, 2012), ou seja, em uma "relação concreta (que) liga o homem à Terra, uma 'geograficidade' (geographicité) do homem como modo de sua existência e de seu destino " (DARDEL, 2015, p. 2).

A ideia de geograficidade é defendida por Eric Dardel (2015) como sendo a ligação que o ser humano estabelece com a paisagem circundante e onde se encontram interligados aspectos objetivos e subjetivos de sua existência. Nesse sentido, o elo humano com o espaço/mundo constitui-se a partir das experiências de lugar nas quais se encontram entrelaçados elementos físicos relacionados ao ambiente e aos indivíduos, assim como as percepções, sensações, pensamentos, sentimentos, imaginação e memória, compondo, assim, horizontes ou paisagens humanas no e do mundo.

O espaço reflete a concepção que cada uma tem acerca de seu lugar no mundo, onde vivenciam relações e experiências pessoais que dão sentido e direcionam sua existência. Assim, a constituição do lugar se dá a partir das experiências, conforme teorizado pelo geógrafo sino-americano Yi-Fu Tuan (2013), um dos pioneiros da Geografia Humanista. Ele emprega a denominação "topofilia" para nomear todos os laços afetivos de identificação e amor por um lugar. Segundo o pesquisador, a topofilia origina-se na vivência humana no lugar. Esclarece, ainda, que o sentimento topofílico não é a mais forte emoção humana, salvo quando "o lugar ou o ambiente é o veículo de acontecimentos emocionalmente fortes ou é percebido como símbolo" (TUAN, 2013, p.136). O vocábulo é um neologismo criado pelo filósofo Gaston Bachelard em sua obra A poética do espaço (2008), como definição de estudo dos espaços amados, felizes. A partir da consolidação da ideia de topofilia nos estudos da Geografia Humanista, convencionou-se chamar de "topofobia" a intensa aversão a um lugar. Dessa forma, pode-se considerar que "conhecer um lugar é desenvolver um sentimento topofílico ou topofóbico" (OLIVEIRA, 2014, p. 12). 
Rev. Interd. em Cult. e Soc. (RICS), São Luís, v. 6, n. 1, p. 173- 186, jan./jun. 2020 ISSN eletrônico: 2447-6498

Complementarmente, explica o geógrafo canadense Edward Relph (2014), o lugar se constitui pelos elos de lugaridade que compõem essas relações experienciais. Esse estudioso associa a definição do lugar à capacidade de reunião de significados decorrentes de experiências, a qual denomina lugaridade. Esse é, para o teórico, o aspecto central desse fenômeno, de tal forma que, sem essa característica, o lugar não existe. Assim, lugaridade é a qualidade inerente ao lugar e se constitui pela combinação dos aspectos, como autenticidade, encontro, sentido de lugar, o espírito do lugar, sendo, com base na lugaridade, identificar ocorrências de lugar-sem-lugaridade e não-lugar. Em oposição extrema, têm-se os lugares autênticos, com forte lugaridade; e os não-lugares, os que não possuem qualquer lugaridade.

Essa perspectiva experiencial pode ser observada por meio das representações artísticas, como ocorre no conto em estudo, no qual se vê que o espaço em torno de Luísa e de sua mãe está além da concretude, de forma que um mesmo espaço central da narrativa, o quarto da mãe idosa, origina lugares distintos para a mãe e para a filha.

\section{A GEOGRAFICIDADE NO CONTO "AS MIMOSAS"}

Nessa densa narrativa, a protagonista Luísa aparece em duas fases distintas de sua vida: ela, adulta, cuidando da mãe senil e, depois, em sua própria velhice. A ação do conto concentra-se em um único espaço físico: o quarto da mãe idosa, onde inicialmente mãe e filha vivenciam ações cotidianas: “Aquele ia ser um domingo como os outros, pensou (Luísa). Até a enfermeira da noite a libertar e ela partir com Simão" (GERSÃO, 2016a, p. 27). Porém, a normalidade da vida das personagens é alterada pelo elemento onírico, associado a um acontecimento fantástico, alterando a realidade ficcional e causando estranhamento na trama por meio de uma insólita passagem de tempo em que Luísa adormece ao lado da mãe e acorda no mesmo espaço físico, mas sozinha e envelhecida.

Tal mudança relaciona-se ao momento da morte da mãe, cuja intensidade pode ser reconhecida pela ausência de narração explícita, somente sugerida pela soma dos elementos e circunstâncias no texto, como a última fala da idosa: "Não me deixes sozinha, acrescentou, apertando-lhe a mão com muita força. Não me deixes sozinha esta noite" (GERSÃO, 2016a, p. 29). Assim como esse fato, os demais acontecimentos do lapso temporal entre o dormir e o acordar não estão explicitamente narrados, mas são de grande importância para a compreensão da condição existencial de Luísa na velhice, exigindo do leitor que participe da construção textual ao fazer a articulação entre os elementos apresentados ao longo da narrativa. 
Rev. Interd. em Cult. e Soc. (RICS), São Luís, v. 6, n. 1, p. 173- 186, jan./jun. 2020 ISSN eletrônico: 2447-6498

No primeiro momento da história, a mãe se recusava a deixar a própria casa para ir morar em um lar de idosos. Como estava inválida, permanecia na cama e o seu quarto era o seu lugar. Nele encontrava o sentido íntimo de lar ao se sentir protegida pela familiaridade e confortada pelos cuidados e pela afetividade que recebia da filha. Tais experiências fortalecem os laços de aconchego, segurança e intimidade fundamentais para que se configure o habitar, e a experiência de lugar tenha sentido de lar.

O quarto refletia a existência da idosa, ligada a outro tempo: "era quase uma sala, de tão grande, [...]. Junto da porta perfilava-se um enorme roupeiro, que seria impossível ter conservado se a casa não fosse antiga e não tivesse tectos tão altos” (GERSÃO, 2016a, p. 25). Seus móveis, quadros, fotografias e demais objetos testemunhavam a história de sua moradora e até lhe faziam companhia, como ela dizia.

Como explica Tuan (2012, p. 90), “a diminuição da mobilidade restringe ainda mais a vida do velho [...] o mundo se contrai não apenas porque seus sentidos perdem acuidade, mas porque seu futuro está truncado: à medida que o futuro diminui, também diminui o espaço horizontal [...]", restando-lhe, assim, buscar a espaciosidade vertical, ou seja, voltar-se à própria subjetividade por meio de pensamentos e lembranças e buscar nas relações interpessoais uma forma de também obter ligação com o mundo.

No contexto da velhice, como analisa Bosi (2006), a memória serve de afirmação da identidade nos espaços sociais do presente vivido, pois reflete representações e significados construídos no passado que reatualizam a própria vida; como a senhora do conto, para quem a filha tanto lia as histórias dos livros quanto contava e recontava tudo o que lembrava, pois “A mãe gostava de histórias antigas. A sua vida eram memórias. O que vinha nos jornais não lhe interessava e a televisão cansava-lhe os olhos [...]" (GERSÃO, 2016a, p. 27).

A idosa não gostava de solidão, mas rejeitava permanecer somente sob os cuidados das enfermeiras. Ela valorizava a companhia de visitas, chegando a monitorá-las em um registro no espelho, sobretudo as da filha, de quem também buscava obter o máximo de atenção possível. Em uma mistura de dependência e exigência, suas atitudes, talvez involuntariamente agravadas por seu estado de saúde, tendiam a monopolizar a filha em torno de si.

No tocante à Luísa, como a relação com a mãe é o elemento central de sua ligação com aquele lugar (o quarto), suas experiências se alteram radicalmente após a morte da idosa, havendo uma notória distinção entre suas sensações espaciais em relação ao espaço do quarto e o mundo exterior. 
Rev. Interd. em Cult. e Soc. (RICS), São Luís, v. 6, n. 1, p. 173- 186, jan./jun. 2020 ISSN eletrônico: $2447-6498$

A filha é uma mulher adulta (o texto não informa, mas sua maturidade sugere isso), é sensível, possui um trabalho e demonstra ser responsável; enfim, uma mulher urbana comum da classe média do século XXI, que se divide entre os cuidados com a mãe doente, seu trabalho, a atenção com a própria saúde e o relacionamento com o noivo Simão. A organização de sua rotina permite evidenciar que ela prioriza o cuidar da mãe. Suas atitudes com ela são de atenção e afeto, porém demonstra sentir desgaste físico e emocional, ansiando pelos momentos em que possa deixá-la sob os cuidados das enfermeiras para sair e se sentir livre e viva. Como ela mesma sintetiza, "Ser filha única não era nada fácil" (GERSÃO, 2016a, p. 24).

Essa ambivalência de sentimentos é o traço marcante na vida da protagonista nesse momento e aparece reiteradamente em algumas imagens, dentre as quais se destacam a das belas, mas sufocantes acácias, e um devaneio em que a filha imaginou-se carregando a mãe nas costas por um campo vazio sem fim, tendo a sensação de "voltar à vida" (p.26) somente ao pensar em seus momentos de amor com o noivo.

Tais elementos compõem a sensação espacial de Luísa, pois aquele quarto era um lugar conflitante para ela, uma vez que nele se inscrevia a vida e a morte de sua mãe. Naquele espaço, cuidava dela com dedicação e lhe proporcionava alguma alegria, mas, inevitavelmente, estar ali era sentir o peso de sua existência cada vez mais afastada da plenitude, seguindo somente ao declínio. O devaneio mostra como a filha se sente nessa rotina penosa e solitária, porque ninguém mais estava lá além da mãe, da filha e, às vezes, das enfermeiras pagas.

Ela era a única responsável pela mãe e, por mais desgastante que fosse essa situação, não se revoltava e claramente não cogitava a possiblidade de abandoná-la. Tentava equilibrar-se entre os anseios de sua própria vida e o apinhamento que aquela situação junto à mãe lhe causava. Nesse contexto, o que lhe trazia certo alento era pensar junto ao noivo, projetando-se fora dali por alguns momentos. Luísa, assim, vivencia distintas sensações de espaciosidade a partir da companhia (a mãe ou o noivo) que focaliza em seu pensamento. Como explica Tuan (2013, p. 84), “As pessoas nos restringem, mas também podem ampliar nosso mundo. O coração e a mente se expandem na presença daqueles que amamos”.

A partir de ideias decorrentes da contraposição entre aparência e essência, a imagem da acácia ou "mimosa" é a referência simbólica de maior importância nesse texto, servindo-lhe de título e sendo um elemento marcante nas experiências de espaço da protagonista. 
Rev. Interd. em Cult. e Soc. (RICS), São Luís, v. 6, n. 1, p. 173- 186, jan./jun. 2020 ISSN eletrônico: $2447-6498$

A primeira experiência retratada se dá em um espaço aberto, no único momento da narrativa em que Luísa está fora da casa da mãe e mostra-se serena. Ela se deslumbra com uma acácia vista de longe e com suas flores em cachos, semelhantes a buquês de noiva. Lembra, então, que são um prenúncio da primavera e, encantada, leva um ramo para decorar a casa. Era o momento da volta de uma caminhada. Ela entra na casa da mãe, põe as flores em uma jarra, mas logo em seguida se sente incomodada com a intensidade do aroma e, em tom racional, põe-se a pensar na violência com que essa planta consome os recursos hídricos e se reproduz, tornando-se nociva também por inviabilizar a sobrevivência de outras espécies, ocasionando, assim, desequilíbrio na biodiversidade.

Esse é o episódio inicial e nele se inscrevem as contraposições centrais da narrativa. Uma é que, considerando as características das acácias, elas podem ser tomadas analogamente aos relacionamentos humanos em geral e, mais especificamente, ao mantido com as mães, pois essas relações são sublimes e benéficas, desde que não vividas em excesso, porque podem impedir que os filhos tenham condições de construir sua própria história de vida. A outra é que, no ambiente externo, espaço em que Luísa está afastada de suas atribuições familiares, os sonhos de se casar e ter a própria família, suscitados a partir da imagem das acácias, são positivos e ela os acolhe, porém, ao serem trazidos para o seu contexto vivido, eles se desarmonizam. O que parecia uma proposta sedutora e agradável de realização, torna-se algo sufocante porque, como comentado anteriormente, Luísa se sente apinhada em sua realidade diária.

Esse momento da narrativa encerra-se com a atitude de Luísa em não descartar as flores de imediato, optando apenas por abrir a janela para arejar o ambiente, uma vez que considera que gostaria de vê-las ao retornar do passeio com o noivo. Isso demonstra sua sensibilidade, mas também certo descompromisso com a busca pela resolução efetiva do que a incomoda, como acontece em relação à monopolização que a mãe exerce sobre sua vida. Situação em que ela apenas cria estratégias paliativas e isso pode tê-la levado, ainda que involuntariamente, a abdicar de suas realizações pessoais.

Para a Geografia Humanista Cultural, "estar perdido" é não ter a noção de qual seja o "seu lugar" e que direções serão seguidas a partir dessa ideia. Sem essa referência, o indivíduo encontra-se reduzido à imobilidade, não somente física e espacial, como também existencial. Assim está Luísa na sequência insólita da narrativa quando acorda e sente "Como se tivesse dormido muitos anos e a vida lhe tivesse fugido, sem se dar conta" (GERSÃO, 2016a, p. 29). Teoricamente ela está no local onde adormecera: o quarto da mãe com os mesmos objetos e móveis, todavia a mãe não está mais na cama e há uma circunstância de 
Rev. Interd. em Cult. e Soc. (RICS), São Luís, v. 6, n. 1, p. 173- 186, jan./jun. 2020 ISSN eletrônico: $2447-6498$

isolamento, pois, inexplicavelmente, a porta e a janela estão trancadas, o local está sem água e sem qualquer comunicação com o exterior, porque o telemóvel está descarregado e não há energia elétrica.

A experiência neste momento relaciona-se ao "despertar" de Luísa para a realidade frente o vazio deixado pela perda da mãe. O que preenchia aquele espaço, dando-lhe significado enquanto lugar, era a existência da mãe, quando tudo remetia a ela, incluindo a filha, cuja história de vida como nessa condição também iria somente até aquele ponto.

Considerando que se a experiência geográfica se altera, o lugar também se transforma. Para a filha, permanecer naquele espaço onde sempre sua existência esteve emparedada, com espaciosidade comprometida, não fazia mais sentido, isso seria reviver e até assumir a experiência da mãe em seu local de finitude. No entanto, outra condição de aprisionamento pesa sobre si: era agora uma idosa.

O conflito vivido pela protagonista aparece transfigurado no espaço da narrativa deste momento: o quarto era um local isolado e de confinamento, a janela e a porta trancadas são referências simbólicas do acirramento da separação entre as realidades interna e externa, corroborando à forma estigmatizada como a sua condição atual (mulher idosa que não constituiu a própria família) é vista pelo mundo.

Ela estava fisicamente aprisionada no lugar onde se manteve psiquicamente presa como filha. Agora que perdera essa função que justificava sua existência, estar nele metaforiza sua inexistência ou irrelevância social, de forma que não está somente posta à margem, mas descartada, fora do mundo: "Mas não podia ficar ali presa. Estava viva e podia lutar” (GERSÃO, 2016a, p. 30). Apegando-se à vida, ela rompe a passividade que a caracterizava e recusa o enquadramento; luta para retirar-se dali, entretanto, por mais que lutasse, ninguém aparecia.

Ao final da narrativa, após diversas tentativas fracassadas de pedido de socorro, a impressão de isolamento torna-se uma desesperadora certeza de condenação à espera pela morte naquele lugar. A sensação de estreiteza existencial é intensificada pelo aroma exalado pelas acácias como uma lembrança angustiante das realizações idealizadas que ela não alcançara. Na tentativa desesperada de romper com a aflição do apinhamento crescente, causado pela perda total da espaciosidade e da lugaridade naquele quarto, a mulher quebra o vidro da janela e salta do quinto andar. O abrupto gesto de suicídio de Luísa é a última imagem do texto. Essa elaboração do desfecho confere à narrativa a intensidade capaz de aproximar o leitor da experiência vivenciada pela personagem que ele acompanhava, de forma 
Rev. Interd. em Cult. e Soc. (RICS), São Luís, v. 6, n. 1, p. 173- 186, jan./jun. 2020 ISSN eletrônico: 2447-6498

que ambos, nesse momento do texto, encontram-se diante do vazio. Efeito que certamente faz a narrativa ressoar em torno das circunstâncias da vida real a que se associa.

O suicídio, no conto, pode ser compreendido como a expressão de extrema infelicidade e uma tentativa radical de finalmente tentar romper com as circunstâncias que a aprisionavam e isolavam. Os acontecimentos do lapso temporal que explicariam a condição de Luísa na velhice não estão narrados claramente no texto, mas é possível inferir que sua frustração decorra do fato de não ter alcançado realizações pessoais que lhe eram significativas e preencheriam sua existência de sentido. Na solidão de sua velhice, Luísa se depara com a evidência de que a desfiguração da própria vida foi a recompensa recebida por ter vivido somente em função de outros e esquecido de si, como normalmente é exigido das mulheres em culturas patriarcais, como observado por Beauvoir (2016).

O que levou Luísa a uma atitude extrema pode estar muito mais relacionado à sua condição feminina no conduzir da própria vida do que à senilidade da mãe, haja vista os aspectos abordados na construção das personagens. Note-se que a mãe não tem nome próprio, o que sugere que sua imagem seja uma representação típica. Suas características estão em consonância com um perfil genérico da velhice em meio à senilidade da mulher, cuja vida seguiu o roteiro previsto pelos padrões sociais tradicionais do mundo ocidental patriarcal. No entanto, a filha, por ser nominalmente referida no texto, tem sua individualidade ressaltada na trama. Seu comportamento pode ser compreendido a partir de escolhas pessoais, o que não implica necessariamente dizer que ela era autônoma e livre, uma vez que o esforço empreendido para corresponder aos papéis sociais femininos de filha, profissional, mulher que se cuida, que mantém relacionamento amoroso bem sucedido e ainda faz planos para o futuro, parece ser uma atitude que mais se aproxima de resignação e passividade ao buscar atender a um padrão do que de liberdade e independência.

Nesse sentido, além dos aspectos já evidenciados ao longo desta análise, há um interessante paralelo entre a condição feminina, em que subjaz certo condicionamento social, da personagem do conto de Teolinda e de duas outras Luísas, a de Eça de Queirós, em $O$ primo Basílio e a do conto "Desencontro" (integrante da obra Tanta gente, Mariana..., 1959), de Maria Judith de Carvalho, pois as três possuem anseios de libertação e felicidade a serem alcançados junto à figura masculina, e todas têm suas expectativas frustradas.

A Luísa do século XIX encontra sua infelicidade tanto no casamento quanto fora dele, ao se deixar levar pela idealização e por sentimentalismo, o que verdadeiramente evidencia que ela somente seguiu a única forma de viver que conhecia devido à educação que 
Rev. Interd. em Cult. e Soc. (RICS), São Luís, v. 6, n. 1, p. 173- 186, jan./jun. 2020 ISSN eletrônico: 2447-6498

recebera e pela tradição de costumes e valores da época em que sua vida de mulher burguesa europeia se inseria.

A Luísa dos anos 60 do século XX, igualmente sob a influência social, passa a vida atormentada em meio ao conflito feminino da inautenticidade, pois, quando jovem, aos dezessete anos, buscou ter o comportamento pudico recomendado à moça que seria digna do casamento, o que serviu de desculpa para que o seu pretendente se afastasse, acusando-a de puritana. Ela passa anos esperando que ele retorne e a valorize como todos the diziam que aconteceria, porém, chegando aos trinta anos, solteira e solitária, entende que, a essa altura da vida, caberia às mulheres corresponderem ardentemente aos homens que por elas ainda se interessassem e assim o faz. Entretanto, em consequência dessa forma de agir, novamente é preterida ao reencontrar-se com aquele que fora seu amor da juventude. A última imagem da mulher na narrativa é muito significativa, pois ela desaparece em meio à multidão, o que remete à condição exata em que sempre esteve: uma pessoa perdida de si mesma por tentar agradar todos, sem nunca se voltar a si mesma.

A Luísa contemporânea também demonstra uma mentalidade ligada ao padrão feminino da tradição patriarcal ao conduzir a própria vida, como demonstra o anseio de se encontrar com o noivo como fuga e proteção do desgaste emocional, provocados pela dedicação à mãe. Essa ideia aparece na imagem referente ao encontro amoroso: "Era isso o que tornavam, amando-se, uma mão enluvada - quente confortável e feliz. Por muito gelado que pudesse ser o mundo em volta" (GERSÃO, 2016a, p. 27). O intento de ter companhia e apoio articula-se à ideia sugerida no nome do amado, Simão, lembrando a figura de Simão Cireneu que, na narrativa bíblica ${ }^{2}$, é obrigado a ajudar Cristo a carregar sua cruz a caminho do Calvário (BÍBLIA, 2017, p. 1585).

No entanto, há elementos dispersos no texto que vão se somando e sugerindo o contrário do almejado pela noiva. A comunicação entre o casal mostra-se prejudicada, assim como o distanciamento pode ser percebido pelo fato de ele não entrar no prédio onde estavam a noiva e sua mãe; logo, ele não se integra à realidade vivida por Luísa. Esse descompasso também aparece nos planos de se casarem no mês de setembro, que é o início do outono em Portugal, a estação que convencionalmente sugere uma metáfora da idade avançada, enquanto um acontecimento tardio. A ideia de desarranjo ganha força pela cobrança que o noivo faz a Luísa quanto ao tempo de espera, informando-lhe gestualmente que já era tarde. Assim, associando esses elementos à condição de isolamento e vazio de Luísa na velhice, tem-se a

${ }^{2}$ Lc 23, 26. 
Rev. Interd. em Cult. e Soc. (RICS), São Luís, v. 6, n. 1, p. 173- 186, jan./jun. 2020

ISSN eletrônico: $2447-6498$

composição de um possível fracasso dessa relação amorosa na qual projetava encontrar companhia e ajuda.

Na tentativa de aproximar a condição feminina dessas Luísas, no tocante a seus anseios e suas ações, embora estejam cronologicamente distanciadas por séculos e a despeito de toda evolução que a humanidade alardeia no século XXI, o conto gersiano evidencia que a força da influência patriarcal, que regia o pensamento no século XIX, alterou-se pouco no século XX e ainda se faz presente na vida e no imaginário feminino na contemporaneidade, induzindo a mulher a não se assumir como sujeito da própria história, deixando, assim, de enfrentar as circunstâncias de sua vida com clareza e autonomia. Como na narrativa, em que a filha assume, solitária e resignadamente, uma série de responsabilidades advindas da complexa inversão de papéis, na medida em que se tornou a mãe de sua mãe.

Evidencia-se, por fim, que não foi a circunstância da velhice da mãe que impediu que a filha obtivesse as realizações e relações necessárias para constituir seu lugar no mundo; esse impedimento corresponde à forma como ela fez isso: esquecendo-se de si mesma, deixando de fortalecer sua própria subjetividade. Ela agiu de acordo com o que está culturalmente inscrito na condição feminina, no contexto tradicional patriarcal, e sentiu intensamente o reflexo de sua trajetória ao chegar à velhice, momento em que o valor da vida humana comumente se precariza, sobretudo dos menos favorecidos cultural e economicamente. Como observa Beauvoir (2016, p. 550-551):

[...] a mulher é um produto elaborado pela civilização; a intervenção de outrem em seu destino é original; se essa ação fosse dirigida de outro modo, levaria a outro resultado. A mulher não se define nem por seus hormônios, nem por misteriosos instintos e sim pela maneira por que reassume, através de consciências alheias, o seu corpo e sua relação com o mundo; [...] Por certo não se deve crer que basta modificar-lhe a situação econômica para que a mulher se transforme: esse fator foi e permanece o fator primordial de sua evolução, mas enquanto não tiver acarretado as consequências morais, sociais, culturais etc. que anuncia e exige, a nova mulher não poderá surgir.

Se comparadas as características de Luísa (tem certa instrução, trabalha fora de casa e é sexualmente resolvida) à forma como negligenciou a condução da própria vida, evidencia-se que o nível do alheamento em que a mulher vive imersa é algo tão arraigado ao funcionamento do mundo, que ela não se deu conta do mal que lhe causava viver somente em função dos outros e não para si. A ideia de outros abrange não somente as pessoas, mas os mecanismos de organização social com base em ideologias e padrões comportamentais que intencionam condicionar a mulher e que são naturalizados a ponto de serem aceitos e assumidos como a orientação natural da vida. Em contraposição, o para si equivale a exercer 
Rev. Interd. em Cult. e Soc. (RICS), São Luís, v. 6, n. 1, p. 173- 186, jan./jun. 2020

ISSN eletrônico: $2447-6498$

sua autonomia e autenticidade, respeitando-se e exigindo que lhe respeitem como ser humano livre (?) e capaz, mas que é falível e limitado, sem que isso seja um defeito.

Belo (2013) destaca que a submissão feminina se inscreve na velhice como um reforço de seu papel de cuidadora afetuosa, doméstica amorosa, passiva e, contraditoriamente, forte para servir de esteio familiar no tocante a serviços e até ao sustento financeiro dos demais familiares, incluindo filhos e netos. Acerca de cuidados da mãe idosa no contexto domiciliar, abordando a realidade brasileira e portuguesa, estudos constatam que esse papel tem sido fundamentalmente exercido por mulheres.

A esse respeito, comenta Teolinda Gersão (2016b, p. 1):

$\mathrm{O}$ facto de vivermos mais tempo, e de as filhas frequentemente assumirem o papel de mães da própria mãe, é um tema incontornável da nossa época. Esse papel não é natural, e não pode ser cumprido sem dor nem sentimentos contraditórios. [...] Isso porque, nesse momento, as filhas mulheres já passaram a vida inteira a cuidar das crianças, dos mais velhos, da casa, da família, da sua vida profissional, e de tudo o mais. E justamente agora, quando têm (ou teriam...) um bocadinho de tempo para si próprias, sem os outros estarem à espera delas, têm novamente de se dividir e de se multiplicar. De repente, a nossa liberdade é limitada por outra pessoa, e isso cria uma enorme sensação de revolta. Queiramos ou não, é humano. Não podemos aceitar ficar ali, porque, se ficamos, não vivemos. Mas abandonar a mãe, não ir vê-la nunca, ou apenas raramente, é uma ideia que nos deprime e rejeitamos [...] A ambiguidade é, portanto, enorme. [...]A sociedade tem que evoluir, dar uma resposta a isso, porque não se pode exigir que sejamos mães das mães[...] E não é justo, nem é humano que a filha deixe de ser ela própria e seja outra vez sacrificada. Essa ideia da mulher que nasceu para se sacrificar pelos outros está ultrapassada. Não aceitamos esse papel. Claro que não recusamos a feminilidade, com tudo o que ela implica, mas sem nos abdicar dos nossos direitos de existir plenamente, como seres inteiros e autónomos.

Assim como reivindica a autora portuguesa, os estudos que abordam a velhice e a mulher idosa no contexto contemporâneo expressam que o indivíduo, à medida que envelhece, vivencia o agravamento de sua condição existencial, de forma que apenas ilusoriamente se pode pensar que o desenvolvimento alcançado pela humanidade, nos campos científico e tecnológico, reflete ou se converte em uma velhice saudável, autônoma e feliz no mundo atual.

\section{CONCLUSÃO}

Considerando as experiências vividas por Luísa, da velhice de sua mãe e a sua própria, é possível compreender que o título "As mimosas" reflete a ambivalência do espaço narrativo onde se acha inscrita a relação entre a filha abnegada que cuida da mãe idosa dependente. A atitude da filha, quando vista superficialmente, parece ser somente um sublime comportamento altruísta e resignado, aliás, como esperado das mulheres, sendo, portanto, 
Rev. Interd. em Cult. e Soc. (RICS), São Luís, v. 6, n. 1, p. 173- 186, jan./jun. 2020 ISSN eletrônico: 2447-6498

totalmente positivo para ambas e para a sociedade. Entretanto, assim como a deslumbrante aparência das acácias ou mimosas esconde uma existência profundamente nociva e predatória, o cuidar da mãe, assumido solitariamente pela filha, é um gesto de grande valor que pode estar mascarando uma situação de sujeição feminina, capaz de monopolizar a existência dessa mulher, de tal forma que ela não consiga desenvolver consistentemente outras relações e realizações que lhe permitam equilibrar sua existência.

No texto, a força necessária para romper com a impassibilidade que pesa sobre a condição feminina e a exclusão sobre a velhice, ambas condensadas na figura de Luísa, vem expressa na radicalidade do suicídio cometido pela protagonista. Esse ato extremo simboliza, nesse caso, que finalmente ela conseguiu ter uma atitude de enfrentamento contra os enquadramentos que lhe foram impostos ao longo de toda a vida e que se intensificaram na velhice, quando ela ainda olha com vivacidade o mundo exterior pela janela, mas se sente completamente excluída dele. Na contemporaneidade, parece que ainda não há um lugar escolhido pelos velhos, mas para os velhos.

\section{REFERÊNCIAS}

BEAUVOIR, Simone de. O segundo sexo: a experiência vivida. Tradução: Sérgio Milliet. 3.ed. Rio de Janeiro: Nova Fronteira, 2016, v.2.

BEAUVOIR, Simone de. A velhice. Tradução: Maria Helena Franco Monteiro. 2.ed. Rio de Janeiro: Nova Fronteira, 2018. (Biblioteca Âurea).

BELO, Isolda. Velhice e mulher: vulnerabilidades e conquistas. Feminismos. Vol.1, n.3, set. - dez, 2013. ISSN: 2317-2932. Disponível em <http://www.feminismos.neim.ufba.br>. Acesso em: 18 ago. 2018.

BÍBLIA. Português. Bíblia sagrada: Bíblia de Aparecida. Tradução de Padre José Raimundo Vidigal. 20. ed. Aparecida - SP: Santuário, 2017, p.1585.

BOSI, Ecléa. Memória e sociedade: lembranças de velhos. 13.ed. São Paulo: Companhia das Letras, 2006.

DARDEL, Eric. O Homem e a Terra: natureza da realidade geográfica. Tradução: Werther Holzer. São Paulo: Perspectiva, 2015.

GERSÃO, Teolinda. As mimosas In: GERSÃO, Teolinda. Prantos, amores e outros desvarios. Porto: Porto Editora, 2016a, p. 23-32.

GERSÃO, Teolinda. Um livro sobre a mãe de todos nós. Lisboa, 2016b. Disponível em: $<$ http://www.bettymilan.com.br/um-livro-sobre-mae-de-todos-nos-teolinda-gersao/>. Acesso em: 10 dez. 2017. 
Rev. Interd. em Cult. e Soc. (RICS), São Luís, v. 6, n. 1, p. 173- 186, jan./jun. 2020 ISSN eletrônico: 2447-6498

OLIVEIRA, Lívia de. O sentido do lugar In: MARANDOLA JR, Eduardo; HOLZER, Werther, OLIVEIRA, Lívia de (orgs). Qual o espaço do lugar?: Geografia, epistemologia, fenomenologia. São Paulo: Perspectiva, 2014, p. 03-14.

RELPH, Edward. Reflexões sobre a emergência, aspectos e essências de Lugar. In: MARANDOLA JR, Eduardo; HOLZER, Werther, OLIVEIRA, Lívia de (orgs). Qual o espaço do lugar?: Geografia, epistemologia, fenomenologia. São Paulo: Perspectiva, 2014, p. 17-32.

TUAN, Yi-Fu. Topofilia: um estudo da percepção, atitudes e valores do meio ambiente. Tradução Lívia de Oliveira. Londrina: Eduel, 2012.

Espaço e lugar: a perspectiva da experiência. Tradução Lívia de Oliveira. Londrina: Eduel, 2013. 